\title{
A rare case of schwannoma mimicking ovarian tumour
}

\author{
Madhusmita Hembram¹, Jayalakshmi Durairaj ${ }^{2 *}$, Dilip Kumar Maurya²
}

${ }^{1}$ Department of Obstetrics and Gynecology, MGMCRI, Pondicherry, India

${ }^{2}$ Department of Obstetrics and Gynecology, JIPMER, Pondicherry, India

Received: 03 June 2017

Accepted: 29 June 2017

\section{*Correspondence:}

Dr. Jayalakshmi Durairaj,

E-mail: dr_jayalakshmi@yahoo.com

Copyright: ( ) the author(s), publisher and licensee Medip Academy. This is an open-access article distributed under the terms of the Creative Commons Attribution Non-Commercial License, which permits unrestricted non-commercial use, distribution, and reproduction in any medium, provided the original work is properly cited.

\begin{abstract}
Ovarian tumor is the most common diagnosis in postmenopausal women, presenting with a pelvic mass, though other surgical causes can still be a remote possibility. We report an extremely rare case of a woman, post hysterectomy, presenting with a pelvic mass where both clinical and radiological evaluations were suggestive of an ovarian tumor. The patient underwent laparotomy and a pre-sacral cystic mass was found and excised. Histopathology revealed a schwannoma as the final diagnosis. Hence, it mandates a high index of suspicion to consider other surgical possibilities, vigilant management in the form of advanced radiological evaluation, especially when dealing with doubtful cases of adnexal tumors prior to surgery.
\end{abstract}

Keywords: Histopathology, Laparotomy, Pre-sacral cystic mass, Schwannoma

\section{INTRODUCTION}

The presentation of vague symptoms such as abdominal distension and pain, often points towards ovarian tumour in a postmenopausal woman with probably malignancy as the provisional diagnosis. Though being the most common possibility, there are several other extraovarian neoplasms, which closely mimic ovarian tumor, posing a diagnostic challenge in certain cases. Here we present a rare case report of pre-saral schwannoma mimicking an ovarian tumor, both clinically and radiologically.

\section{CASE REPORT}

A 50-year-old multiparous woman, having undergone hysterectomy 16 years back for fibroid uterus, presented to gynecology department with complains of pain lower abdomen for 4 months and distension of abdomen since 3 months. There was no history of any vaginal discharge, bleeding per vaginum (BPV), loss of appetite, bony pain or any gastrointestinal symptoms. Her bladder and bowel habits were normal. On examination, she was moderately built and nourished. There was no pallor, clubbing, edema or any significant lymphadenopathy. On per abdominal examination, there was a vague mass palpable on the right iliac fossa measuring $8 \times 7 \times 6 \mathrm{cms}$. There was no ascites or any other organomegaly. A per speculum examination revealed a healthy vault. On bimanual examination, there was a fixed cystic mass felt through the pouch of Douglas and the same was felt on rectal examination. Her CA -125 and CEA levels were within normal limits. On USG, a complex cyst measuring $7 X 7.9 \mathrm{~cm}$ was observed in the pelvis and both the ovaries were not separately visualized. A CECT was done and the report showed an $8.5 \times 7 \mathrm{~cm}$ multiloculated pelvic mass posterior to the bladder. There was post contrast enhancement of solid components and septae. Focal areas of calcification were also noted in the mass and septae. Fat plane between bladder and rectum was maintained and there was no significant lymphadenopathy (Figure 1, Figure 2). A Staging laparotomy was performed with ovarian tumour as the provisional diagnosis. Intraoperatively, both ovaries were visualized and found to be atrophic. A presacral cystic mass was found, considering the possibility of a retroperitoneal mass, cystectomy was performed successfully after controlling 
the oozing from presacral veins by packing with hemostatic gels.

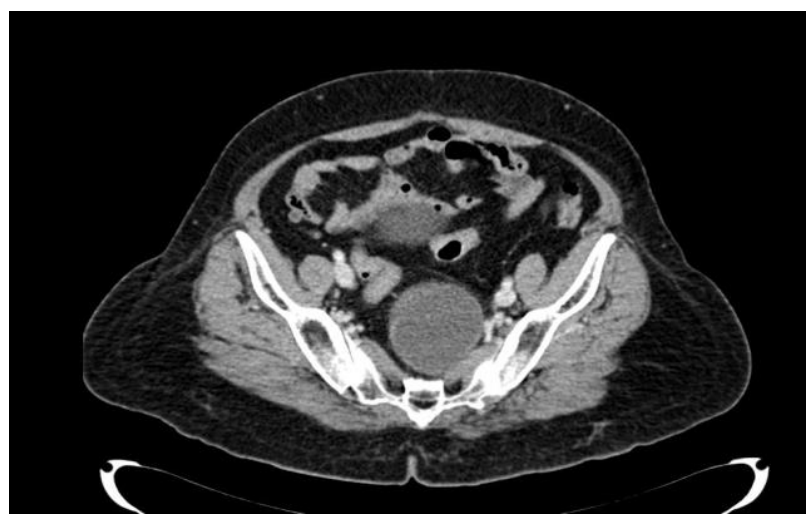

Figure 1: CT abdomen showing cross sectional view of presacral mass.

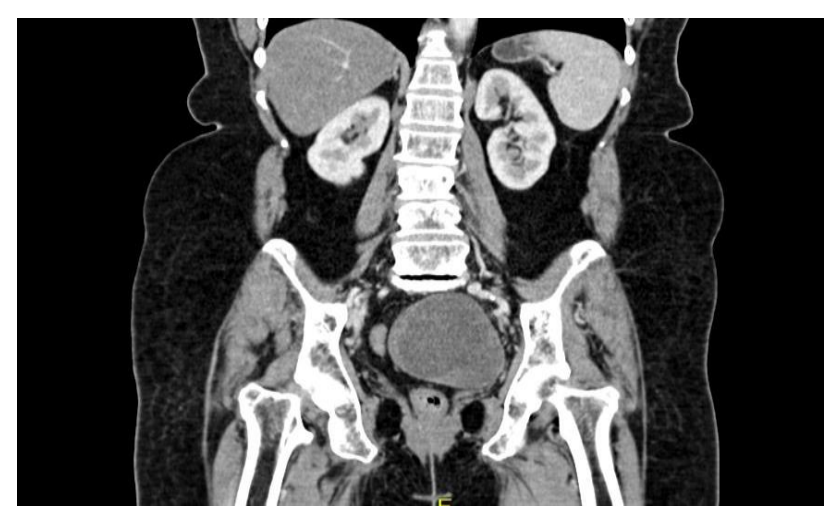

Figure 2: CT abdomen showing coronal view of presacral mass.

Her post-operative period was uneventful and she was discharged on the 10th postoperative day. Histopathogical examination of the cystic mass showed findings typical of schwannoma, which are compact cellular tissues (Antoni A areas, Figure 3) and loose hypocellular myxoid lesions with microcystic spaces (Antoni B areas, Figure 4).

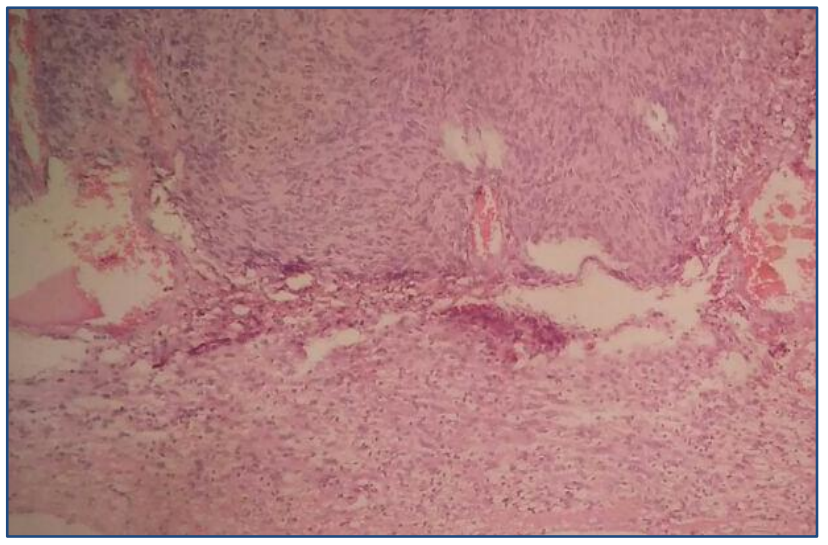

Figure 3: Microscopy showing antoni A area.

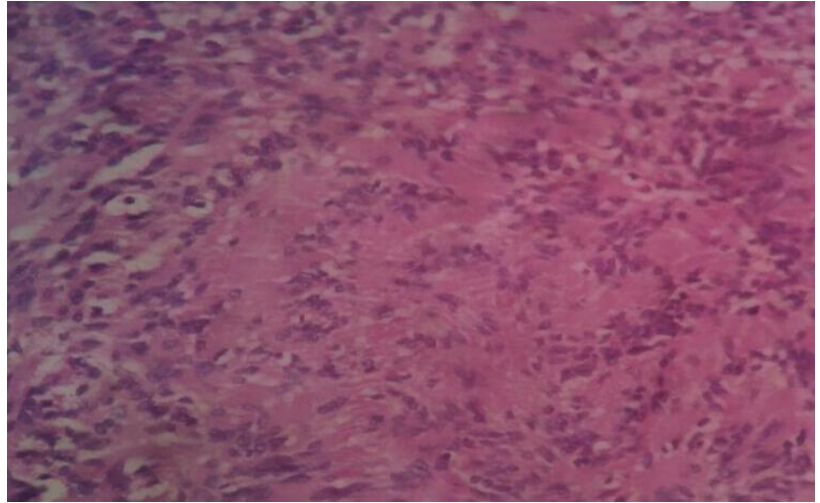

Figure 4: Microscopy showing antoni B area.

The patient was reviewed after six weeks, her abdominal wound had healed well.

\section{DISCUSSION}

Schwannoma in neurilemoma are benign tumours arising from the Schwann cells which form myelin sheath around peripheral nerve, with a female gender predominance. ${ }^{1}$ Most common site of occurrence are head and neck region and flexor surfaces of extremities. ${ }^{2}$ Retroperitoneal presentation is rare comprising $0.7 \%-1.7 \%$ of all retroperitoneal tumors. ${ }^{3}$ Retroperitoneal schwannoma can occur in paravertebral and presacral region and is benign most commonly by nature. ${ }^{4}$ Calcification is seen in $23 \%$ of cases and cystic degeneration in almost $60 \%$ of cases. ${ }^{5}$ Schwannoma rarely presents with neurological symptoms. ${ }^{6}$

The presentation is usually secondary to local mass effect or is an incidental finding. ${ }^{7}$ Growth of schwanomma is slow and hence does not show any specific symptomatology, except for pressure symtoms. ${ }^{8}$ There has been a case, report, where schwannoma mimicked dermoid cyst during pregnancy. ${ }^{9}$ Schwannoma mimicking adrenal tumours has also been reported. ${ }^{10}$ In a Srilankan case report, the patient presented with constipation due to a giant presacral schwannoma. ${ }^{11}$ There has also been a case report, where sacral schwannoma mimicked an aneurysmal bone cyst. ${ }^{12}$

Another similar case of retroperitoneal mass obliterating the rectouterine pouch was found to be a degenerated cystic schwannoma in a young woman. ${ }^{13}$ A doubtful case of pelvic mass been followed up for four years, turned out to be suggestive of schwannoma at a later date and was left for conservative management due to anticipate difficult surgery. ${ }^{14}$

There are very few case reports of schwannoma presenting in post-menopausal women, one among which was thought to be a leiomyosarcoma and hysterectomy was performed followed by radiotherapy and it was only later, when a residual tumor excision clinched the diagnosis of schwannoma. ${ }^{15}$ Similarly, enbloc excision of 
parametrial tumor along with TAH with BSO in a 58year-old woman, revealed a schwannoma on histopathology. ${ }^{16}$

Our case report is the first one to be found in an elderly post hysterectomy patient, mimicking an ovarian tumor and had a complete excision with no residual disease. Though pre-surgical diagnosis is difficult due to absence of distinguishing features between schwannoma and other soft tissue tumours by different imaging methods. ${ }^{17}$

According to some reports, MRI has better visualisation. ${ }^{6}$ CT could not differentiate schwannoma from ovarian in our case report, which may be due to absence of certain characteristic radiological signs of schwannoma in retroperitoneal location, such as target and fascicle signs. ${ }^{18} \mathrm{CT}$ guided biopsy and FNAC are not very promising for pre-operative diagnosis. ${ }^{19}$ Having diagnosed, the recommended treatment is complete surgical excision. ${ }^{20}$

There is $5 \%-10 \%$ chance of recurrence, if not resected completely. ${ }^{21,22}$ In the present case, we could achieve successful complete excision of the tumor inspite of the dangerous location. Though benign schwannoma has a good prognosis, malignant schwannoma is resistant to chemotherapy and radiotherapy, hence have poor prognosis. $^{4}$

\section{CONCLUSION}

As many extra ovarian pathologies can mimick ovarian tumour, a proper radiological imaging with analytical approach to anatomical and tissue features of pelvic mass is mandatory.

In difficult anatomical spaces, diagnostic laparoscopy would enable us to differentiate between ovarian and other extraovarian pathologies for optimal care, as different surgical approach and dedicated surgical expertise may be needed in various such conditions.

Funding: No funding sources

Conflict of interest: None declared

Ethical approval: Not required

\section{REFERENCES}

1. Kapan M, Onder A, Gummu M, Gumu H, Girgin S. Retroperitoneal schwannoma. JSCR. 2011.10:1

2. Adlekha S, Chadha T. Cellular Schwannoma Arising from Sigmoid Mesocolon Presenting as Torsion. Ann Med Health Sci Res. 2013;3(suppl1):S33-S4.

3. Tortorelli AP, Papa V, rosa F, Pacelli, Doglietto GB. Imaging of the month-retroperitoneal schwannoam. Arc Surg. 2006;141:1259-61.

4. Li Q, gao C, Hao X. Analysis of 82 cases of retroperitoneal schwannoma. ANZ J Surg. 2007;77: 237-40.
5. Beaman FD, Krandorf MJ, Menke DM. Schwannoma: radiologic-pathologic correlation. Radiographics. 2004;24:1477-81.

6. Goh BKP. Tan Y, Ching YA, Chow PKH, Ooi LPS, Wong WK. Retroperitoneal schwannoma. The Am J of Surg. 2006;192:14-8.

7. Choudry HA, Nikfarjam M, Liang JJ, Kimchi ET, Conter R, Gusani NJ, et al. Doiagnosis and management of retroperitoneal ancient schwannoma. World J Surgic Oncol. 2009;7:12.

8. Theodopoulos T, Stafyla VK, Tricuntoula P, Yiallourou A, Marinius A, Kon di- pafitis A et al. Special problems encountering surgical management of large retroperitoneal schwannoma. World J Surg Onc. 2008;6:107.

9. Ibraheim M, Ikomi A, Khan F. A pelvic retoperitoneal schwannoma mimicking an ovarian dermoid cysy in pregnancy. J Obstet Gynaecol. 2005;25:620-1.

10. Maeshima $S$, Nakamura $H$, Nishikawa M, Murakami $\mathrm{T}$, Mitani T, Marukawa $\mathrm{T}$ et al. Retroperitoneal schwannoma simulating adrenal tumour. Clinical imaging. 1992;16(2):121-4.

11. Samarakoon L, Weerasekear A, Sanjeewa R, Kollure S. Giant presacral schwannoma presenting with constipation: a case report. J Medic Case reports. 2012;6:285.

12. Cho DY, Hur JW, Shin JH, Kim JS. A case report and review of literatures. $\mathbf{J}$ Korean Neurol. 2013;54:350-4.

13. Aran T, Guven S, Gocer S, Ersoz S, Bozkaya H. Large retroperitoneal schwannoma mimicking ovarian carcinoma: case report and literature review. Eur J Gynaecol Oncol. 2009;30(4):446-8.

14. Yadav Y, Onon T, Sukumar S. Conservative management of a pelvic Schwannoma presenting as an adnexal mass. J Obstet Gynaecol. 2008;28(3): 364-5.

15. Tomao F, Mariani L, Miele E, Spinelli GP, Tomao S. Retroperitoneal schwannoma presenting as an ovarian tumour. Eur J Gynecol Oncol. 2006;27(2):185-7.

16. Machairiotis N, Zarogoulidis P, Stylianaki A, Karatrasoglou E, Sotiropoulo G, Floresho A et al. Pelvic schwannoma in the right parametrium. Int $\mathbf{J}$ Gen Med. 2013;6:123-6.

17. Hughes MJ, Thomas JM, Fisher C, Moskovic EC. Imaging features of retroperitoneal and pelvic schwannomas. Clin Radiol. 2005;60:886-93.

18. Wong CS, Chu TYC, Tam KF. Retroperitoneal schwannoma: a common tumour in an uncommon site. Hong Kong Med J. 2010;16(1):66-8.

19. Kishi Y, Kajiwara S, Seta S, Kawauchi N, Suzuki T, Sasaki K. Retroperitoneal schwannoma misdiagnosed as a psoas abscess: report of case. Surg Today. 2002;32:849-52.

20. Nah YW, Suh Jh, Choi DH, Ko BK, Kim GY, Im $\mathrm{YC}$, et al. Benign retroperitoneal schwannoma: surgical consideration. Hepatogastroenterology. 2005;52(66):1681-4. 
21. Song JY, Kim SY, Park EGK, Kim CJ, Kim DG, Lee HK,. Schwannoma in the retroperitoneum. J Obstet Gynaecol. 2007;33:371-75.

22. Maneschq C, Roqatsch H, Bartsch G, Stenzl A. Treatment of giant ancient pelvic schwannoma. Tech Urol. 2001;7(4):296-8.
Cite this article as: Hembram M, Durairaj J, Maurya DK. A rare case of schwannoma mimicking ovarian tumour. Int J Reprod Contracept Obstet Gynecol 2017;6:3695-8. 